\title{
Preface
}

Bristol is the city that John Cabot sailed from and Thomas Chatterton dreamed, that Hugh Latimer preached to and Oliver Cromwell seized, that entertained Parliaments in the Middle Ages and rioted for Reform in the nineteenth century. Since the Norman Conquest, it has always had an important place in English history, experiencing events and contributing to developments that stirred the nation. What follows is an account of its connection with one small piece of that history, the rise of the Atlantic economy in the early modern period and the accompanying transformation of English economic ideas and practices. But this book is not about economics alone. It is grounded on the belief that we can no more abstract the economy from politics, culture, and society than we can separate intentional human action from thought and judgment. It also rejects the notion that the life of a city like Bristol could ever be treated as a self-contained whole. Instead it views such cities as social organisms living in close relationship with their surroundings. What gives them their structure is the set of internal codes they carry. And what enables them to survive is their ability to adapt to or transform their environment, which itself is always changing.

It was beyond my capacity to write this kind of history encyclopedically. Even if the evidence necessary to define every relevant interrelationship had survived-it has not-I could not have distilled it all into words. Hence in place of a comprehensive treatment analyzing every aspect of Bristol's history in depth, I offer an extended essay, one that attempts to turn what I have been able to learn about early modern Bristol 
into a coherent story. Given the city's importance in this period, a number of such stories were possible, each with different terminal dates and a different emphasis. But the one that interested me most was Bristol's transition from medieval trading center to Atlantic entrepôt. This development has important implications for our understanding of the growth of capitalism in England, for it allows us to see how "merchant capital"- that weak limb of capitalism, according to many scholars 1 - fit into the social and political order of the sixteenth and seventeenth centuries and helped to transform it. This book, then, is an essay in the local history of capitalism, viewing this historical development from the perspective of a provincial town in the west of England whose traders long had looked to the Atlantic for their livelihoods. As such, it centers the story of this great transformation far from the financial, commercial, and manufacturing capitals of Europe where other important processes of economic, social, intellectual, and political change were under way.

Ever since Marx, the history of capitalism has been a central subject for all students of early modern European history. But its study has oscillated among only a limited number of established positions. On the one hand, there has been a lengthy debate-primarily among Marxists-about whether the transition to capitalism arises principally from internal contradictions within the feudal order or from the dissolution of feudal relationships produced by the so-called commercial revolution. On the other, there has been an equally lengthy debate-this time primarily between Marxists and non-Marxists such as Max Weber and his followers-about whether we should look for the origins of capitalism principally in material changes in the economy or in spiritual changes in mentalité and moral outlook. Fruitful as these controversies have been in unearthing new knowledge, they seem forever to repeat themselves, despite employing hitherto unknown facts and more and more refined terminologies. Such repetition generally signals a problem less of inadequate evidence than of conceptualization. A hidden assumption or a false dichotomization makes resolution of the debate impossible.

The history of Bristol between 1450 and 1700 offers a way out of this dilemma, since developments there defy conventionally accepted distinctions between internal and external forces. In their place, the evidence reveals a strong pattern of reciprocal relationships between the city and the wider world that shaped contemporary outlooks and in turn were affected by them. Bristol's story, then, provided a good opportunity to rethink some of the heretofore unresolved issues posed by the 
development of modern capitalism. This book is the result. It does not purport to give a final answer to any question, but if it has succeeded in casting some fresh light on its subject I shall be pleased.

Because this history seeks to explain an economic transformation, its starting place is the central economic fact of Bristol's fifteenth-century history: England's loss of Bordeaux in 1453. Thereafter the narrative unfolds by examining the complex interplay of economic, social, cultural, and political changes that followed this event. Part 1 traces the rivalry between Bristol's merchants and shopkeepers that emerged as the city adapted to a new pattern of trade in the sixteenth century. Part 2 looks to the prevailing patterns of culture in the city in the later Middle Ages, focusing especially on ideas of community and authority. It considers how these concepts and the practices associated with them changed during the sixteenth and early seventeenth centuries. In Part 3, the story moves into the second half of the seventeenth century, concentrating on the 1660 s and 1670 s, to explore how the peculiar structural features of the city's life that had emerged in the Elizabethan and early Stuart era came undone as the growth of the Atlantic economy went hand in hand with the establishment of a new kind of politics and prompted the development of new ways of economic thought and action. The book concludes by considering the state of social and economic understanding in Bristol at the end of the seventeenth century.

The approach I have followed has meant giving primacy to the longterm economic history of Bristol while omitting to mention the Exclusion Crisis and the Glorious Revolution and relegating the Reformation and the Civil War to a secondary position. The danger is that these important occurrences will therefore be thought of as no more than effects of the economic history recounted here. Nothing could be further from my intention. The story told by this book is one of human choices, not of determinism. But to develop its theme, many important subjects have had to be presented only as subordinate, not independent, topics. Other books written for different purposes surely will give those subjects the central position and full treatment they deserve, and in such works my own subject no doubt will be mentioned only in passing.

A word should perhaps be said about the relation of this volume to "cultural poetics." This term has been used primarily in studies of literary culture. What has it to do with a book about urban history in which reliance on the techniques and scholarly equipment of the social scientist is so evident? Or, to put this point the other way around, why should a work concerned with a form of cultural interpretation depend 
so much on statistical tables? How can they aid, to use Stephen Greenblatt's words, in studying "the collective making of distinct cultural practices" and inquiring "into the relations among these practices"?? These questions are especially grounded in the recent development of economic history as a field. In the 1930s, as F. J. Fisher has pointed out,

the main requirement of an economic historian was that he should be able to read, since most of his sources were literary. The archetype of the learned monograph consisted of a thin rivulet of text meandering through wide and lush meadows of footnotes. ... Today, the first requirement of an economic historian is that he should be able to count, for his materials are largely statistical. The archetype of our modern fashion is one in which a stream, often a less than limpid stream, of text tumbles from table to table and swirls around graph after graph. ${ }^{3}$

As the scope of economic history has widened, and as its reliance on economic theory has grown, this assessment has become almost a truism. Economic history is now more properly denominated "quantitative history" or, as Robert Fogel has called it, "new economic history"-history, as it were, by equation. "This highly sophisticated approach has generated many new and important insights into the study of economic laws and practices. But for all its technical brilliance, it has not solved the historian's main problem, which remains interpretive, not statistical. The figures having been collected, what do they mean? Given the time, the place, and the enterprise, should we have expected the results we found, or do they require further explanation? As always, the most important questions call upon our understanding and not just our analytical skills, so arriving at a satisfactory account of our subject demands comprehension of the milieu and the motives of the participants, and not just measurement of structures and conjunctures. ${ }^{5}$ To grasp the meaning and significance of economic history requires a careful attention to the changing norms of the market and their relation to broad developments in religion, society, and politics that the term "cultural poetics" captures very effectively. Put another way, economic history demands attention to literary documents and cultural artifacts as well as statistical sources, and an ability to read and observe as well as to count.

What, then, of the connection of this book to the so-called New Historicism itself? As used among literary critics, this term usually refers to an interest in historically grounded studies of ideology and power in cultural production. For many historians, however, the concept of historicism stands for two seemingly contradictory-and equally nox- 
ious-notions. On the one hand, it refers to a form of determinism which argues that history reveals discoverable rhythms and patterns to human life or is governed by discernible laws of social development. On the other, it refers to a form of relativism. The truths it unearths are time-bound; they depend on differences in culture and on the particular historical situation in which events occur or institutions are found. When put together, these two notions lead to a highly artificial view in which each period is reified into a self-standing historical object with its own spirit or principle of organization that fits into a deterministic evolutionary scheme. The end result is a necessary progress of ideas, an iron logic of modes, a forced march of social development in discrete stages.

Nevertheless, it would be impossible to study history without accepting some elements of the historicist's view. The foundation of historical scholarship, as Marc Bloch argues in The Historian's Craft, is that it is about human beings living in time. But this simple truth, which every working historian would probably accept, is no mere truism, since "historical time" understood in Bloch's sense is not an abstraction-not a simple unit of measurement-but, as Bloch says, "a concrete and living reality with an irreversible onward rush. It is the very plasma in which events are immersed, and the field in which they become intelligible." Accordingly, it demonstrates continuity, in that one event may lead to others, and it reveals difference, in that periods or cultures are shown to have self-standing characters arising and disappearing in "the uninterrupted sequence of the ages." But even though "a historical phenomenon can never be understood apart from its moment in time," a given moment can either unite a particular phenomenon with or separate it from what had come before and what would follow. For historians, then, the "very raison d'être" of scholarship is to be able to decide, as Bloch says, "to what extent ... the connection which the flow of time sets between" two consecutive periods predominates or fails to predominate "over the differences born out of the same flow[.] Should the knowledge of earlier periods be considered indispensable or superfluous for the understanding of the later?" This view of historical time transforms historicism into a methodology, a source of research questions rather than of metaphysical certainties. ${ }^{6}$

Employed in this heuristic fashion, historicism of Bloch's kind simultaneously recognizes the importance of historical causality in shaping events and the possibility that their consequences might have been otherwise. This book proceeds from a similar perspective. It aims to 
account for historical change without assuming its inevitability or explaining away its significance. It rests on the conviction that a culture is not simply a collection of norms and values but a complex and continuously altering arrangement of beliefs and practices governing the whole of social life. This kind of culture is neither monolithic nor uncontested. As Stephen Greenblatt has stressed, every aspect of it involves negotiation: "a subtle, elusive set of exchanges, a network of trades and trade-offs, a jostling of competing representations" that takes place in time and that is repeated and developed across time. ${ }^{7}$ To grasp the nature of this process requires attention to nuances of meaning, to caesurae in meter and to ambiguities of manner in what is said and done. Although many New Historicists will find this book concerned with issues far different from their usual fare and employing methods not normally encountered in cultural studies, and others no doubt will disagree with its emphasis on contingent events and human choices and intentions, all should recognize a reliance on common assumptions about the importance of historical understanding in interpreting cultural processes.

This kind of historical understanding proceeds from what might be called a position of methodological realism, a sense of the past as independent of ourselves, a sense that it is capable of teaching us something about the possibilities of human life that we can discover in no other way. Those of us who study history in this fashion write as though we are describing and analyzing places we might actually have visited. Our professed goal is to illuminate what happened to the people who lived there, to see how the events that affected them unfolded, and to account for why they took the course they did. Hence, our scholarly disputes normally are more about whether we have gotten the story right than about the theories we have employed in reaching our conclusions. We worry about anachronism, about distinguishing between our ways of living and those followed by the societies we study. Some practitioners of this approach even try "to vanish before their subjects," as Steven Ozment has said. ${ }^{8}$

Nevertheless, it is a mistake to treat the past as a metaphysical entity, cut off from the present, existing timelessly in independence of our minds and methods-something we can actually recover whole whenever sufficient evidence has survived. What we know of any past culture or society is available to us because of the remnants it has left behind: its texts, its documents, its artifacts. The significance of these items becomes apparent only by virtue of the questions we ask and the techniques we use to answer them. It depends on interpretation, an always daunting task that we would not escape even if by some miraculous 
means we could be transported in time to view history as it happened. We would still find ourselves, as do historians of contemporary events, translating back and forth from our own social and cultural frameworks to what we can understand of the meanings and purposes of our subjects. Our questions and techniques arise because of our particular interests in the past, which depend on our motives-often ideological as well as academic - for studying it. These in turn vary according to history and therefore according to our relation to the past itself. In consequence, we can never actually see the world through the eyes of our subjects, although we sometimes insist that we should try. We can only imagine how it might have appeared to them, depending as best we can on our critical self-awareness to correct the distortions created by our biases and prejudices. But we can never erase ourselves entirely from what we study. Nor should we want to. ${ }^{9}$

It is never easy to say where a project such as the present one found its origin. In one sense, it began in the late Professor W. K. Jordan's graduate seminar at Harvard, in which I wrote a paper on Bristol in the Civil War. This research so intrigued me that upon its completion I made it the proposed subject of my dissertation. But my first foray into English archives taught me a salutary lesson. Nearly everything I had concluded about Bristol from printed sources quickly came undone when I saw my first manuscripts, and the social and political divisions I had established in my seminar paper turned out to be illusory. What had seemed a plausible way to cover the facts I had gleaned from the books in Widener Library could in no way account for the evidence I had now discovered. Gradually, however, a new understanding emerged, one beginning with the perception that early modern English cities were, not self-contained social organisms, but places open to the wider world of national and even international affairs. My Ph.D. thesis, completed under Professor Wallace MacCaffrey's direction and subsequently published in a dissertation series, explored the implications of this view of urban society for the lives and outlooks of the Bristolians, never reaching the Civil War period about which I had first intended to write. ${ }^{10}$ But using 1640 as a terminal date created something of a false sense of finality to the story, since events in the late 1630s seemed to settle all the outstanding political and economic issues of Bristol's history in the later sixteenth and the early seventeenth century. Of course this was only an artifact of the chronological limits of the study; the Civil War and its aftermath almost immediately undid nearly 
all that happened. Upon completing my dissertation, then, I was left with the dilemma of how to deal with this awkward fact.

The solution came somewhat serendipitously in response to an inquiry from Bernard Bailyn, who had read my dissertation soon after its completion. He was interested in Bristol's role in American immigration during the later seventeenth century and wanted to know something about its system for registering indentured servants bound for the American plantations. During my research $I$ had made some notes about the origins of this system in 1654 but had given little thought to them at the time. When looked at closely, however, this registration scheme posed a genuine puzzle, since, as is argued in Chapter 8 , the remedy it instituted simply did not fit the crime it claimed to punish. What, then, was this ordinance about and what had provoked it? Discovery of the case that had brought the Bristol Common Council to action began to reveal what was at stake, since the main targets of the registration scheme turned out to be interlopers in overseas trade and sectaries as well. In 1654 the activities of these individuals were highlighted at the calling of the first Protectorate Parliament, the elections for which in Bristol had produced victory for conservative merchants and outraged protest from the city's radicals and sectaries. Many of these radicals turned out to be important colonial traders who frequently supplied indentured labor to the American market. In this light the ordinance and the register seemed designed less to protect servants than to control the traders; it was not so much a mechanism of economic regulation as a weapon of political attack.

Once I had reached this conclusion, much else began to become clear about the role of American trade in Bristol's life. The nature of the American market, I realized, made it impossible to regulate trade with it under the rules on which Bristol's major overseas merchants had previously relied. As a result, their victories in the late 1630 s were incapable of coping with the new economic order taking shape among the colonial traders. I knew then that I had a solution to the dilemma posed by my dissertation, and I began pursuing the implications of my findings where they would lead. This book is the outcome.

\section{A NOTE ON DATES AND QUOTATIONS}

Unless otherwise indicated, all dates are given Old Style, except that the year is taken to begin on 1 January. Spelling and punctuation in the quotations follow the original, but I have expanded the abbreviations. 